\title{
Perbandingan Pengaruh Model Pembelajaran Gerakan Sholat Berbasis Multimedia dengan Deskripsi Fundamental Pada Pendidikan Anak Usia Dini
}

\author{
Sekreningsih Nita ${ }^{1}$, Hermawati Dwi Susari² \\ ${ }_{1,2}$ Univesitas PGRI Madiun \\ ㅁnita@unipma.ac.id, ${ }^{2}$ dwisusari@unipma.ac.id
}

\begin{abstract}
Abstrak
Penelitian ini dilakukan dengan tujuan untuk mengetahui perbandingan pengaruh model pembelajaran berbasis multimedia dengan deskripsi fundamental pada pendidikan anak usia dini. Desain rancangan penelitian menggunakan pre-test dan posttest, pre-test digunakan untuk mengetahui tingkat kesetaran dari masing-masing populasi dalam memahami materi gerakan sholat yang akan disampaikan. Sedangkan post-test dilakukan untuk mendapatkan hasil belajar siswa yang digunakan untuk menganalisa dalam menguji hipotesa yang diajukan. Populasi dalam penelitian ini adalah siswa RA Al-Hadiid kelas A berusia 5 tahun yang terbagi untuk kelas kontrol 20 anak dan kelas eksperimen 25 anak, sehingga total populasi 45 anak yang sudah diuji tingkat homogenitasnya. Sedangkan untuk mengetahui hasil akhir antara kelas kontrol dengan kelas eksperiment dilakukan Uji Anovauntuk proses pengambilan keputusan menerima atau menolak hipotesis yang telah diajukan..Hasil akhir untuk semua populasi dari uji hipotesisada kenaikan antara nilai rerata pre-test dan post-test yaitu 2.54 kelas eksperimen (multimedia) dan 2,31 untuk kelas kontrol (konvensional).
\end{abstract}

Kata kunci: multimedia, metode deskripsi fundamenal, uji anova.

\section{PENDAHULUAN}

Pembelajaran harus dirancang dan dilaksanakan oleh pendidik agar dapat memenuhi amanat peraturan pemerintah yang tecantum dalam Undang - Undang Republik Indonesia nomor 20 Tahun 2003 tentang Sistem Pendidikan pasal 39 ayat 1 menyebutkan bahwa tenaga kependidikan bertugas melaksanakan administrasi, pengelolaan, pengembangan, pengawasan, dan pelayanan teknis untuk menunjang proses pendidikan pada satuan pendidikan. Proses pembelajaran terjadi karena adanya komunikasi antara pendidik dan peserta didik. Namun dalam proses pembelajaran tidak selamanya dapat berjalan dengan lancar. Oleh karena itu seorang pendidik harus mempunyai strategi pembelajaran yang tepat sehingga dapat mendukung dalam kegiatan pembelajaran.Dengan adanya perkembangan teknologi yang semakin mutakhir diberbagai sektor termasuk dunia pendidikan memerlukan adanya inovasi media pembelajaran yang dapat digunakan untuk meningkatkan kualitas pembelajaran.Salah satu produk teknologi yang dapat digunakan sebagai inovasi dalam pembelajaran adalah perangkat lunak multimedia interaktif berbasis komputer.

Berdasarkan hasil observasi dan wawancara yang dilakukan di lapangan maka diidentifikasi berbagai masalah yang terjadi di RA Al-Hadiid Kota Madiun, yaitu: 1) Apakah ada kenaikan secara signifikan diatas 0.05 pada nilai pre-test maupun posttest dari hasil belajar gerakan sholat dengan menggunakan strategi pembelajaran berbasis multimedia ?, 2) Apakah strategi pembelajaran berbasis multimedia dengan strategi berbasis deskriptif fundamental (konvensional) dapat memberikan peran penting terhadap hasil belajar siswa pada materi gerakan sholat?. 


\section{TINJAUAN PUSTAKA}

Secara umum multimedia adalah kombinasi penggunaan media yang berisi teks, grafik, gambar, video dan suara untuk menyajikan informasi. Erna Hidayati (2010) dengan nim A53C090001, Jurusan Pendidikan Anak Usia Dini, Fakultas Keguruan dan Ilmu Pendidikan, Universitas Muhammadiyah Surakarta, mengatakan bahwa Pendidikan anak usia dini sangat penting karena pada masa ini merupakan Golden age (usia emas) yang hanya datang sekali dan tidak dapat diulangi, yang sangat menentukan untuk pengembangan kualitas manusia selanjutnya. Selli Mariko (2014: 133-139) mengatakan bahwa Proses pembelajaran harus dirancang dan dilaksanakan oleh pendidik supaya dapat memenuhi amanat peraturan pemerintah. Kegiatan belajar mengajar harus dapat mengoptimalkan semua potensi peserta didik untuk menguasai kompetensi yang diharapkan. Dalam Ni Made Suryaningsih (2016), menjelaskan bahwa pelaksanaan pendidikan untuk anak usia dini masih cenderung menggunakan metode pembelajaran konvensional dengan pendekatan teacher centered. Hal ini mengakibatkan selama proses pembelajaran siswa lebih banyak diam dan kurang berani menyampaikan pendapat dan ide-idenya. Berdasarkan permasalahan tersebut, maka guru hendaknya memberikan motivasi didalam pembelajaran, sehingga menciptakan pembelajaran yang berpusat pada siswa (I K G Marga Sudiartha, 2016)

Berdasarkan penjelasan di atas, dapat disimpulkan bahwa media pembelajaran yang digunakan sangat berperan penting dalam pencapaian hasil yang diharapkan. Dengan kata lain, kehadiran media pembelajaran sangat membantu dalam pencapaian tujuan pembelajaran. Salah satu jenis media pembelajaran adalah media pembelajaran berbasis Multimedia. Dengan kata lain, multimedia pembelajaran berguna untuk menyalurkan pesan (pengetahuan, keterampilan , dan sikap) serta dapat merangsang pilihan, perasaan, perhatian dan kemauan siswa sehingga secara sengaja proses belajar terjadi, bertujuan, dan terkendali (Galuh Kartikasari, 2016).

\section{METODE PENELITIAN}

Dalam penelitian ini peneliti menggunakan metode eksperimen semu (quasi eksperiment) yang terdiri dari satu variabel bebas (variabel independent), satu variabel kontrol dan satu variabel terikat (variabel dependent) yang sudah ditentukan secara jelas dan tegas. Sedangkan variabel bebasnya adalah strategi pembelajaran dengan berbasis multimedia, satu variabel kontrol dengan strategi pembelajaran tatap muka (konvensional) dengan menggunakan modul.Adapun variabel terikatnya dengan hasil belajar.

Rancangan atau desainnya menggunakan prestest postest only design. Dimana Prestest disini digunakan untuk mengetahui tingkat kesetaraan dari masingmasing populasi dalam memahami materi yang akan disampaikan. Kemudian dilakukan postest untuk mendapatkan hasil belajar yang akan digunakan dalam menganalisa dan menguji hipotesis yang diajukan.

Teknik Sampling yang digunakan dalam penelitian ini dengan mengambil populasi dari siswa yang mengikuti pembelajaran gerakan sholat dari kelas A berusia 5 tahun yang terbagi menjadi 2 kelas A1 sebanyak 20 anak untuk kelas kontrol dan kelas A2 sebanyak 25 anak untuk kelas eksperimen. Jadi total kedua kelas tersebut sebanyak 45 anak yang berasal dari populasi homogen yang sudah dilakukan uji homogenitas prestest. Untuk lebih jelasnya metode penelitian yang digunakan adalah Metode Ekperimen Semu dengan Teknik Sampling seperti tergambar di bawah ini 


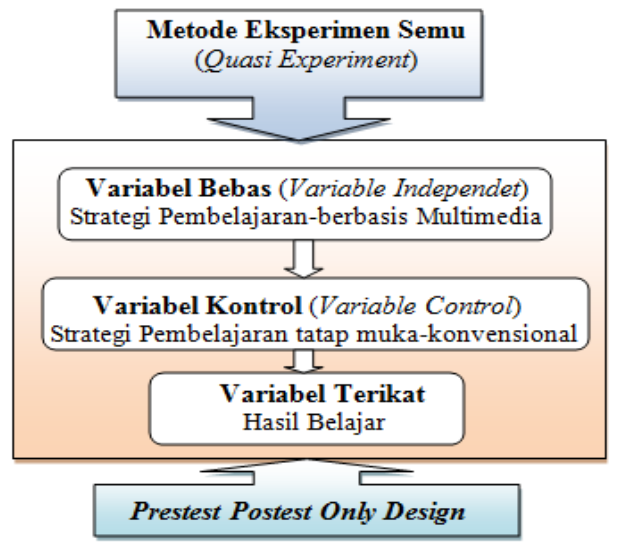

Gambar 1. Rancangan Penelitian-Teknik Sampling

\section{Teknik Analisa Data}

Langkah-langkah dalam analisa data agar dapat ditarik kesimpulan antara lain :

1. Despkripsi Statistik : tahap pembuatan tabulasi data untuk setiap variabel penelitian, pengurutan data secara interval dan disusun dalam bentuk tabel distribusi frekuensi, untuk mencari mean, median, modus dan simpangan baku.

2. Uji Prasyarat Analilsis : Sugiyono (2008:138), mengatakan bahwa sebelum pengujian hipotesis terlebih dahulu dilakukan uji normalitas dan uji homogenitas varians. Uji normalitas digunakan untuk mengetahui apakah data setiap variabel penelitian yang akan dianalisis membentuk distribusi normal sedangkan uji homogenitas varians digunakan untuk mengetahui apakah varians sampel yang akan dikomparasikan itu homogen atau tidak.

3. Uji Hipotesis : menggunakan uji ANOVA satu faktor atau disebut juga dengan uji ANOVA desain random keseluruhan. Dilakukan ini untuk proses pengambilan keputusan menerima atau menolak hipotesis yang telah diajukan

\section{HASIL DAN PEMBAHASAN.}

Hasil analisa kelas kontrol.

Tabel-1 : Hasil Uji Normalitas Pre \& Post Test

\begin{tabular}{|c|l|l|l|l|}
\hline \multicolumn{2}{|c|}{ Kelas-A } & \multicolumn{3}{|c|}{$\begin{array}{c}\text { Kolmogorov- } \\
\text { Smimov (a) }\end{array}$} \\
\cline { 3 - 5 } \multicolumn{2}{|c|}{} & Statistik & df & sig \\
\hline Pre-Test & $\begin{array}{l}\text { Kelas Kontrol } \\
\text { (konvensional) }\end{array}$ & 0.14 & 20 & 0.20 \\
\hline Post-test & $\begin{array}{l}\text { Kelas Kontrol } \\
\text { (konvensional) }\end{array}$ & 0.13 & 20 & 0.20 \\
\hline
\end{tabular}

Konsep dasar uji normalitas Kolmogorov Smirnov adalah membandingkan distribusi data yang akan diuji normalitasnya dengan distribusi normal baku. Pada tabel-1 diatas baik pre-test maupun post-test sudah diuji data hasil penelitian pada kelas kontrol,. Hasil analisis data pre-test dan post-test kelas kontrol menunjukkan nilai signifikan 0.20. Nilai df pada kelas kontrol sebanyak 20 sesuai sampel yang diujikan. Penerapan pada uji Kolmogorov Smirnov adalah jika signifikansi di bawah 0.05 berarti data yang akan diuji mempunyai perbedaan yang signifikan dengan data normal baku, berarti data tersebut tidak normal. Pada tabel-1 hasil analisis menunjukkan nilai signifikansi 0.20 berarti lebih besar dari 0.05 maka data pada nilai pre-test maupun post-test dapat disimpulkan sudah terdistribusi normal.

Tabel-2 : Statistik Deskriptif Pre-Test dan Post- Test Kelas Kontrol.

\begin{tabular}{lllll}
\hline \multicolumn{1}{c}{ Uji Test } & \multicolumn{2}{c}{ Pre-Test } & \multicolumn{2}{c}{ Post-Test } \\
\multicolumn{1}{c}{ Kelas } & Statistik & $\begin{array}{l}\text { Std } \\
\text { Error }\end{array}$ & Statistik & $\begin{array}{l}\text { Std } \\
\text { Error }\end{array}$ \\
\hline Hasil Belajar & & & & \\
Kelas Kontrol: & & & & \\
Mean & 0.6 & 0.019 & 2.91 & 0.23 \\
Median & 0.63 & - & 2.70 & \\
Mode & 0.5333 & - & 2.7 & \\
Variance & 0.0054 & - & 1.38 & \\
Std Deviation & 0.073 & - & 1.176 & \\
Minimum & 0.53 & - & 1.0 & \\
Maximum & 0.73 & - & 4.7 & \\
Range & 0.20 & - & 3.7 & \\
Sum & 3.73 & - & 61.20 & \\
\hline
\end{tabular}


Hasil Analisis Statistik Deskriptif Pre-Test dan Post-Test Kelas Kontrol dari Tabel-2 diatas menyatakan bahwa Nilai Mean (ratarata) $=0.6$ dengan std error $=0.019$ untuk pre-test sedangkan untuk post-test nilai rata-rata $=2.91$ dengan std error $=0.23$. Std error of mean digunakan untuk memeriksa besar rata-rata populasi yang diperkirakan dari sampel, dengan std error of mean tertentu pada tingkat kepercayaan 95\%. Setelah data diurutkan untuk kelas kontrol ini didapat nilai tengah (median) untuk pretest $=0.63$ dan untuk post test $=2.7$. Sedangkan nilai yang seringkali muncul (mode) untuk pre-test $=0.53$ dan post test $=2.7$. Variansi atau tingkat keragaman pada data pre-test $=0.0054$ dan variansi post test $=1.38$ pada kelas kontrol.Semakin tinggi nilai variance berarti semakin bervariasi dan beragam suatu data. Std Deviation adalah nilai yang digunakan untuk acuan sebaran data , untuk data pre-test $=0.073$ dan nilai post test $=1.176$ pada kelas kontrol. Selanjutnya untuk nilai minimum data pretest $=0.53$ dan post-test $=1.0$ dan untuk nilai maximum data pre-test $=0.73$ dan nilai post-test nya $=4.7$. Jadi jarak nilai tertinggi dan terendah pada data pre-test $=0.20$ dan post-test $=3.7$. Jumlah semua data (sum) pada data pre-test $=3.73$ dan post-test $=$ 61.2 .

\section{Hasil Analisa Kelas Eksperimen..}

Tabel-3 : Hasil Uji Normalitas Pre-test dan Post-test Kelas Eksperimen.

\begin{tabular}{|c|l|l|l|l|}
\hline \multicolumn{2}{|c|}{} & \multicolumn{3}{c|}{$\begin{array}{c}\text { Kolmogorov- } \\
\text { Smimov (a) }\end{array}$} \\
\cline { 3 - 5 } \multicolumn{2}{|c|}{ Kelas-B } & Statistik & df & sig \\
\hline Pre-Test & $\begin{array}{l}\text { Kelas } \\
\text { Eksperimen } \\
\text { (multimedia) }\end{array}$ & 0.153 & 25 & 0.128 \\
\hline Post-test & $\begin{array}{l}\text { Kelas } \\
\text { Eksperimen } \\
\text { (multimedia) }\end{array}$ & 0.146 & 25 & 0.170 \\
\hline
\end{tabular}

Pada Tabel-3 diatas, baik data pre-test maupun post-test sudah diujikan untuk data hasil penelitian pada kelas eksperimen.
Hasil analisis menunjukkan nilai signifikan= 0,128 dari data pre-test dan post-test $=$ 0.170. Nilai df sebesar 25 yang mengindikasikan jumlah sampel yang diuji pada kelas eksperimen sebanyak 25 sampel. Penerapan pada uji Kolmogorov Smirnov adalah jika nilai signifikansi di bawah 0.05 berarti data yang akan diuji mempunyai perbedaan yang signifikan dengan data normal baku, berarti data tersebut tidak normal. Pada hasil analisis menunjukkan nilai signifikansi sebesar 0.128 dan 0.170 yang berarti lebih dari 0.05 , maka data pada nilai pre-test dan post-test dinyatakan sudah terdistribusi normal.

Tabel-4 : Statistik Deskriptif Pre-Test dan Post-Test Kelas Eksperimen.

\begin{tabular}{lllll}
\hline \multicolumn{1}{c}{ Uji Test } & \multicolumn{2}{c}{ Pre-Test } & \multicolumn{2}{c}{ Post-Test } \\
\multicolumn{1}{c}{ Kelas } & Statistik & $\begin{array}{l}\text { Std } \\
\text { Error }\end{array}$ & Statistik & $\begin{array}{l}\text { Std } \\
\text { Error }\end{array}$ \\
\hline Hasil Belajar & & & & \\
Kelas & & & & \\
Eksperimen & & & & \\
(multimedia) & & & & \\
Mean & 0.56 & 0.043 & 3.10 & 0.195 \\
Median & 0.50 & - & 3.30 & \\
Mode & 0.40 & - & 2.3 & \\
Variance & 0.03 & - & 0.951 & \\
Std Deviation & 0.166 & - & 0.9751 & \\
Minimum & 0.40 & - & 1.3 & \\
Maximum & 0.80 & - & 5.0 & \\
Range & 0.40 & - & 3.7 & \\
Sum & 3.33 & - & 77.50 & \\
\hline
\end{tabular}

Hasil keluaran dari data Statistik Deskriptif Pre-Test dan Post-Test Kelas Eksperimen dari tabel-4 diatas adalah :Untuk nilai mean (rata-rata) dari pre-test $=0.56$ dengan Std Error of Mean $=0.043$, sedangkan nilai ratarata dari post-test untuk kelas eksperimen $=3.10$ dengan std error $=0.195$.Penggunaan std error of mean adalah untuk memeriksa besar rata-rata populasi yang diperkirakan dari sampel. Untuk itu dengan std error of mean tertentu dan pada tingkat kepercayaan sebesari 95\%. Setelah data diurutkan untuk kelas eksperimen ini diperoleh nilai tengah (median) pada pretest $=0.50$ dan post-test $=3.30$. Nilai yang 
seringkali muncul (mode) untuk pre-test $=$ 0.40 dan post-test $=$ 2.3. Sedangkan variance atau tingkat keragaman pada kelas eksperimen ini, untukdata pre-test $=0.03$ dan post-test $=0.951$. Semakin tinggi nilai variance berarti semakin bervariasi dan beragam suatu data. Std Deviation merupakan nilai yang digunakan untuk acuan sebaran data pre-test $=0.166$ dan post-test $=0.9751$ untuk kelas eksperimen . Untuk nilai terendah (minimum) pada kelas ekperimen dari data pre-test $=0.40$ dan post-test 1.3. Sedangkan untuk nilai tertinggi (maksimum) pre-test $=0.80 \mathrm{dan}$ post-test $=5.0$. Berikutnya Jarak nilai tertinggi dan terendah (range) pada data pre-test $=0.40$ dan post-test $=3.4$. Jadi jumlah semua data (sum) pada kelas eksperimen data pre-test $=3.33$ dan data post-test $=77.5$

Tabel-5 : Hasil Analisis Kovarian Nilai PostTest.

\begin{tabular}{llllll}
\hline & $\begin{array}{l}\text { Sum } \\
\text { of } \\
\text { Square }\end{array}$ & df & $\begin{array}{l}\text { Mean } \\
\text { Square }\end{array}$ & F & Sig \\
\hline $\begin{array}{l}\text { Between } \\
\text { Groups }\end{array}$ & 3.69 & 2 & 1.845 & 1.547 & .055 \\
$\begin{array}{l}\text { Within } \\
\text { Groups }\end{array}$ & 22.71 & 19.02 & 1.194 & & \\
\hline
\end{tabular}

Kesimpulan dan pengambilan keputusan yang dapat diambil berdasarkan uji sstatistik pada tabel 5 diatas terhadap uji hipotesis dilakukan pada taraf signifikansi 5\% (0.05). Jika hasil analisis menunjukkan nilai Sig lebih besar dari alpha 5\% (0.05) maka $\mathrm{H}_{0}$ diterima. Namun jika hasil analisis menunjukkan nilai Sig lebih kecil dari alpha 5\% (0.05) maka $\mathrm{H}_{0}$ ditolak.Secara lengkap hasil analisis kovarian (ANOVA) dengan skor post-test seperti pada tabel-5 di atas.Pada kolom Sig terlihat nilai signifikansi sebesar Sig (0.055) $>\Psi$ (0.05), hal ini mengandung arti bahwa hipotesis $\mathrm{H}_{0}$ diterima $\mathrm{H}_{1}$ ditolak. Kesimpulan dari analisis uji hipotesis ini adalah strategi pembelajaran berbasis komputer tidak terdapat pengaruh yang positif dan signifikansi terhadap pre-test hasil belajar untuk materi gerakan sholat.

Dari hasil observasi yang telah peneliti lakukan, didapat beberapa faktor yang menyebabkan hasil belajar siswa tidak terdapat perbedaan yang signifikan untuk materi gerakan sholat.Faktor penyebabnya ada pada peran guru, yang sangat berpengaruh pada penciptaan lingkungan belajar yang kondusif. Paradigma oleh guru kelas masih belum berubah dalam proses pembelajaran, selama ini yang dilakukan masih bersifat informatifsatu arah, guru menerangkan dan siswa mendengarkan dan ketika guru menerapkan strategi baru dalam proses pembelajaran ada rasa keengganan untuk belajar bagi siswa. Ada beberapa faktor yang menyebabkan strategi pembelajaran berbasis multimedia tidak dapat menaikkan secara signifinikanpada hasil belajar siswa khususnya untuk materi gerakan sholat yaitu:

1. Untuk siswa, belum bisa secara mandiri belajar dengan berbagai strategi pembelajaran yang sesuai agar siswa mampu mengarahkan, memotoviasi dan mengatur dirinya sendiri dalam pembelajaran.

2. Untuk guru kelas, belum bias mengembangkan ilmu pengetahuan dan ketrampilan khususnya dibidang TIK dalam memfasilitasi pembelajaran, memahami belajar dan hal-hal yang dibutuhkan dalam pembelajaran.

\section{SIMPULAN DAN SARAN}

Sebagai kesimpulan hasil dari uji hipotesis dan pembahasan diatas adalah sebagai berikut:

1. Untuk semua populasi ada kenaikan hasil belajar antara nilai re-rata pre-test dan post-test yaitu pada kelas experimen dengan strategi pembelajaran berbasis multimedia sebesar $=2.54$ dan pada kelas kontrol dengan strategi pembelajara berbasis diskripsi fundamental (modul) 
sebesar= 2.31. Oleh karena itu dapat disimpulkan bahwa kelas eksperimen memiliki kenaikan hasil belajar yang lebih tinggi.

2. Hasil untuk siswa yang diajar dengan strategi pembelajaran berbasis multimedia dengan basis modul, tidak terdapat perbedaan yang signifikansi. Terlihat dari hasil analisis menggunakan Anova menunjukkan nilai sig. 0,055 (melebihi taraf signifikansii yang telah ditetapkan). Artinya penggunaan strategi pembelajaran dengan multimedia tidak dapat menaikkan hasil belajar secara signifikan dibanding dengan strategi pembelajaran dengan modul (secara deskripsi fundamental).

\section{SARAN}

1. Untuk siswa agar dapat membangun motivasi dirinya sendiri maka variasi pembelajaran bisa ditambahkan dengan metode quiz game tentang sholat dengan rewards point untuk setiap jawaban.

2. Bagi guru kelas dapat mengembangkan potensi diri dengan banyak mengikuti pelatihan-pelatihan tentang konsep pembelajaran berbasis teknologi informasi.

\section{DAFTAR PUSTAKA}

Hidayati, E, Media Pembelajaran Shalat Bagi Anak Berbasis Multimedia, 2010, Journal Speed-Sentra Penelitian Engineering dan Edukasi, Vol. 2, No. 2
Kartikasari, G., 2016, Pengaruh Media Pembelajaran Berbasis Multimedia Terhadap Motivasi dah Hasil Belajar Materi Sistem PencernaanManusia, Studi Eksperimen pada siswa Kelas V MI Miftahul Huda Pandantoyo, Dinamika Penelitian, Vol. 16, No.1.

Mariko, S., 2014, Pengaruh Srategi Pembelajaran Berbasis Multimedia Interaktif terhadap Hasil Belajar Fisika pada Materi Optika Geomatri, Jurnal Formatif 4(2): 133-139, ISSN : 2088$351 X$

Sudiartha, M., I.K.G., 2016, Perancangan dan Implementasi Media Pembelajaran Pengenalan aksara Bali Berbasis Multimedia, Jurnal Matrix, Vol.6, No.1.

Sugiyono. 2008. Metode Penelitian Kuantitatif, Kualitatif, dan R \& D. Bandung: Penerbit Alfabeta.

Suryaningsih, N.M.A., Cahaya, I.M.E., Poerwati, C.E., 2016, Implemenasi Pembelajaran Inkuiri Terbimbing Berbasis Permaianan dalam meningkatkan Kreativitas Anak Usia Dini, Vol.5, No.2, ISSN 2303-288X. 